\title{
High Temperature Oxidation Behavior of the AISI 430A and AISI 430E Stainless Steels in $\mathrm{Ar} / \mathrm{H}_{2} / \mathrm{H}_{2} \mathrm{O}$ Atmosphere
}

\author{
Maria de Fátima Salgado , Antônio Claret Soares Sabioni ${ }^{\mathrm{a} *}$, Anne-Marie Huntz ${ }^{\mathrm{b}}$, Édson Hugo Rossi \\ a Laboratório de Difusão em Materiais, Departamento de Física, ICEB, \\ Universidade Federal de Ouro Preto - UFOP, REDEMAT, 35400-000 Ouro Preto - MG, Brazil \\ ${ }^{\mathrm{b}}$ Laboratoire d'Étude des Matériaux Hors-Équilibre - LEMHE, \\ CNRS ICMMO UMR 8182, Université Paris XI, 91405, Orsay, France \\ 'Arcelor Mittal Timóteo, 35180-018 Timóteo - MG, Brazil
}

Received: December 17, 2007; Revised: March 17, 2008

\begin{abstract}
The high temperature oxidation behavior of two ferritic stainless steels type AISI 430A and AISI 430E is examined at low oxygen pressure and high temperatures. The AISI 430A steel is ferritic up to $860{ }^{\circ} \mathrm{C}$. Above this temperature, this steel is bi-phased: presence of austenite and ferrite phases. The 430E steel is stabilized with $\mathrm{Nb}$, and is ferritic at all temperatures. The oxidation experiments were performed in a thermobalance SETARAM TGDTA 92, in the range of $850-950{ }^{\circ} \mathrm{C}$, in $\mathrm{Ar} / \mathrm{H}_{2} / \mathrm{H}_{2} \mathrm{O}$ atmosphere, under oxygen partial pressures lower than $1.3 \times 10^{-18} \mathrm{~atm}$. The microstructure and the composition of the oxide scales were analysed by scanning electronic microscopy (SEM) and energy dispersive spectroscopy (EDS). Different oxidation behaviors in AISI 430A and AISI $430 \mathrm{E}$ stainless steels were observed. At $850{ }^{\circ} \mathrm{C}$, the oxidation of the $430 \mathrm{~A}$ steel is greater than that of the $430 \mathrm{E}$ steel, but above $900{ }^{\circ} \mathrm{C}$ the oxidation of the $430 \mathrm{~A}$ steels is lower than that of the $430 \mathrm{E}$ steel. The oxidation rate of the 430A steel shows low dependence on temperature, while the oxidation of the 430E follows an Arrhenius law, with an activation energy corresponding to the chromia scale growth.
\end{abstract}

Keywords: oxidation, low oxygen pressure, ferritic stainless steel, AISI 430A, AISI 430E

\section{Introduction}

Austenitic stainless steels are traditionally used for industrial applications at high temperatures. However, they have been progressively replaced by ferritic stainless steels of lower cost, due to the absence of nickel ${ }^{1}$. Therefore, it is important to characterize the oxidation behavior of ferritic stainless steels at high temperatures in different partial oxygen pressures. In many applications of stainless steels at high temperatures, such steels are subjected to aggressive hot gases in which the oxygen partial pressure is very low. The oxygen partial pressure of the atmosphere may affects not only the oxidation kinetics, but also the nature of the oxide film and, as a consequence, the chemical and physical properties of the oxide scale grown on the stainless steels. Previous studies on oxidation of the AISI 304 and AISI 439 stainless steels showed that the oxidation kinetics of the AISI 439 ferritic steel do not significantly depend on the oxygen pressure, while the oxidation kinetics of the AISI 304 austenitic steel significantly varies with the oxygen pressure ${ }^{1,2}$. Under very low oxygen pressures, in an $\mathrm{Ar} / \mathrm{H}_{2} / \mathrm{H}_{2} \mathrm{O}$ atmosphere, as used in the present work, the AISI 304 austenitic steel presents higher oxidation resistance than the AISI 439 ferritic steel in the temperature range of 850 to $950{ }^{\circ} \mathrm{C}^{1,2}$. In this work, the high temperature oxidation behavior of two ferritic stainless steels, type AISI 430A and AISI $430 \mathrm{E}$, are examined at low oxygen pressure and high temperatures. The AISI 430A steel is ferritic up to $860^{\circ} \mathrm{C}$. Above this temperature, this steel has a partial ferrite to austenite phase transformation, and is then bi-phased: presence of austenite and ferrite ${ }^{3}$. The $430 \mathrm{E}$ steel is stabilized with $\mathrm{Nb}$, and is ferritic at all temperatures ${ }^{3}$. The results obtained for the oxidation of the 430A and 430E steels are discussed and compared to the oxidation behavior of the AISI 439 ferritic stain- less steel stabilized with $\mathrm{Ti}$ and $\mathrm{Nb}$, designed for industrial applications at high temperatures, and for which the oxidation behavior in $\mathrm{Ar} / \mathrm{H}_{2} / \mathrm{H}_{2} \mathrm{O}$ atmosphere is known $n^{1,2}$.

\section{Experimental}

The AISI 430A and AISI 430E ferritic stainless steels were supplied by Arcelor Mittal Timóteo. The chemical analyses of these steels are given in Table 1. The samples were cut with the dimensions of $10 \times 10 \times 0.6 \mathrm{~mm}$. A hole of $0.8 \mathrm{~mm}$ in diameter was drilled near an edge at the center of the sample in order to hang the sample in the thermobalance by means of a platinum wire. The samples were grinded with 1100 and $1200 \mathrm{SiC}$ paper, and then polished with diamond paste of 3 and $1 \mu \mathrm{m}$. The polished samples were submitted to oxidation treatments in a thermobalance SETARAM TGDTA 92, whose sensibility is equal to $\pm 1 \mu \mathrm{g}$. The oxidation isothermal treatments were performed at 850,900 and $950{ }^{\circ} \mathrm{C}$, in $\mathrm{Ar} / \mathrm{H}_{2} / \mathrm{H}_{2} \mathrm{O}$ atmospheres, for 50 hours. This atmosphere was obtained by passing $\mathrm{Ar} / \mathrm{H}_{2}$ mixture through a cryostat at $-60^{\circ} \mathrm{C}$, in which an $\mathrm{H}_{2} \mathrm{O}$ vapour pressure is maintained at $5.26 \times 10^{-6} \mathrm{~atm}$. Then, an equilibrium, $\mathrm{H}_{2}+1 / 2 \mathrm{O}_{2} \leftrightarrow \mathrm{H}_{2} \mathrm{O}$, is established in the furnace that leads to very low oxygen partial pressures of $1.46 \times 10^{-20} \mathrm{~atm}$ at $850^{\circ} \mathrm{C}, 1.38 \times 10^{-19}$ atm at $900{ }^{\circ} \mathrm{C}$, and $1.3 \times 10^{-18}$ atm at $950{ }^{\circ} \mathrm{C}$. The growth kinectics of the oxide scales formed on the steels were established from thermogravimetric analyses by measuring the mass gain per unit area $(\Delta \mathrm{M} / \mathrm{S})$ versus oxidation time $(\mathrm{t})$. The microstructure and the composition of the oxide scales were analysed by scanning electronic microscopy (SEM) and energy dispersive spectroscopy (EDS). 


\section{Results}

\subsection{Oxidation kinetics}

Figures 1 and 2 show the thermogravimetric analyses of the AISI 430A and AISI 430E stainless steels, respectively, after oxidation at 850,900 and $950{ }^{\circ} \mathrm{C}$, in $\mathrm{Ar} / \mathrm{H}_{2} / \mathrm{H}_{2} \mathrm{O}$, for 50 hours. It is worth noting that for the AISI $430 \mathrm{~A}$ steel the oxidation rate at $850{ }^{\circ} \mathrm{C}$ is greater than that at $900{ }^{\circ} \mathrm{C}$ after an oxidation time of 5200 seconds. This surprising behavior of the 430A steel may be due to a phase transformation at ca. $860{ }^{\circ} \mathrm{C}$ of the ferritic structure into ferritic/austenitic biphased structure.

Table 1. Chemical composition of the $430 \mathrm{~A}$ and $430 \mathrm{E}$ Stainless Steels (wt. $(\%)$ ).

\begin{tabular}{ccccccc}
\hline $\begin{array}{c}\text { Stainless } \\
\text { steel }\end{array}$ & $\mathrm{C}(\%)$ & $\mathrm{Mn}(\%)$ & $\mathrm{Si}(\%)$ & $\mathrm{Cr}(\%)$ & $\mathrm{Nb}(\%)$ & $\mathrm{N}(\mathrm{ppm})$ \\
\hline $430 \mathrm{~A}$ & 0.05 & 0.40 & 0.35 & 16.10 & - & 510 \\
$430 \mathrm{E}$ & 0.02 & 0.18 & 0.30 & 16.20 & 0.40 & 220 \\
\hline
\end{tabular}

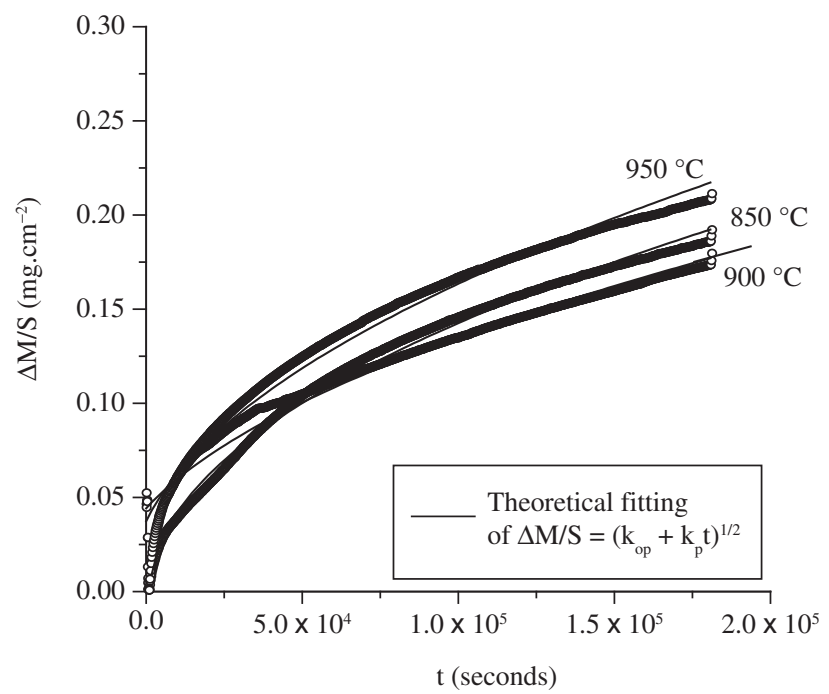

Figure 1. Thermogravimetric analysis for the oxidation of the $430 \mathrm{~A}$ steel in $\mathrm{Ar} / \mathrm{H}_{2} / \mathrm{H}_{2} \mathrm{O}$.

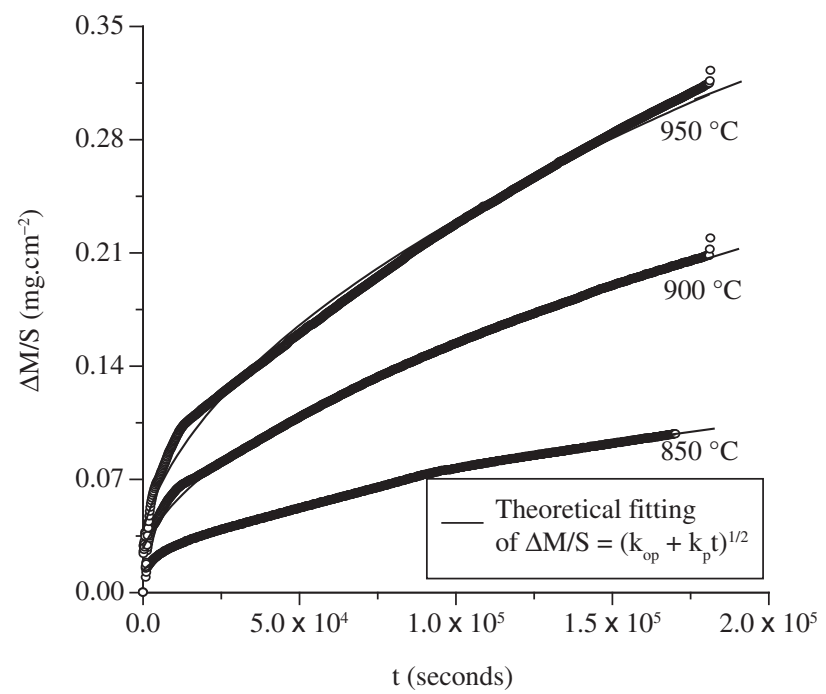

Figure 2. Thermogravimetric analysis for the oxidation of the $430 \mathrm{E}$ steel in $\mathrm{Ar} / \mathrm{H}_{2} / \mathrm{H}_{2} \mathrm{O}$.
In all cases, a linear relationship between $(\Delta M / S)^{2}$, the mass variation per surface unit, and the oxidation time $(\mathrm{t})$ is practically observed, at least in a second stage. It means that, for the experimental conditions used in this work, the oxidation kinetics follow a parabolic law, given by $(\Delta \mathrm{M} / \mathrm{S})^{2}=\mathrm{k}_{\mathrm{op}}+\mathrm{k}_{\mathrm{p}} \mathrm{t}$, where $\mathrm{k}_{\mathrm{p}}$ is the parabolic oxidation constant, and $\mathrm{k}_{\text {op }}$ is a constant. A parabolic law cannot be observed at $\mathrm{t}=0$ as it would correspond to an infinite oxidation rate. Thus, there is always a first stage, which is more or less long, in the oxidation kinetics. Another explanation for the deviation of the experimental curves from the theoretical fittings, in the initial stage of the oxidation, is that a complete law may be obtained due to the superimposition of a linear law and a parabolic one; after some time, the linear term becomes negligible compared to the parabolic one. So, in all cases, the parabolic oxidation constant deduced from the second stage can be considered as available.

When the oxide growth follows a parabolic law, the oxidation kinetics is controlled by oxygen and/or cation diffusion through the oxide scale ${ }^{4}$. In this case, the parabolic constant may be defined as a function of the inward oxygen diffusion and of the outward chromium (or iron) diffusion through the scale by using the Wagner's theory for metal oxidation ${ }^{5}$. The parabolic oxidation constants were determined by fitting the relationship $\Delta \mathrm{M} / \mathrm{S}=\left(\mathrm{k}_{\mathrm{op}}+\mathrm{k}_{\mathrm{p}} \mathrm{t}\right)^{1 / 2}$, by non-linear regression, to the experimental data of $\Delta \mathrm{M} / \mathrm{S}$ versus $\mathrm{t}$ of the plots of the Figures 1 and 2, where the fitted curves are also shown. The obtained $\mathrm{k}_{\mathrm{p}}$ values from plots of Figures 1 and 2 are listed in Table 2.

\subsection{Microstructure and composition of the oxide scales}

On both steels and after oxidation for 50 hours at all temperatures, a continuous oxide film is formed on the 430A and 430E stainless steels. In the temperature range and oxygen partial pressure used in this work, chromia is thermodynamically stable, while iron oxide is unstable ${ }^{2}$. Consequently, chromium should be the major component of the oxide scale grown by oxidation. EDS analysis confirmed chromium as the major component of the oxide scale. Some Mn and $\mathrm{Fe}$ were also observed on the oxidized surface for both steels. $\mathrm{Nb}$ was not detected by EDS on the oxide films formed on the $430 \mathrm{E}$ steel. Figures 3a,c and Figures $4 a, c$ show the microstructures of the oxidized surfaces and the EDS analysis for the 430A and 430E steels, respectively. It can be noticed that the microstructure of the oxide formed on AISI $430 \mathrm{~A}$ at $850{ }^{\circ} \mathrm{C}$ is similar to that obtained at $950{ }^{\circ} \mathrm{C}$, while the morphology of the oxide formed at $900{ }^{\circ} \mathrm{C}$ is somewhat different.

\section{Discussion}

For both steels and at all tested temperatures, the oxide film is mainly constituted of chromia, which is in agreement with the values of the parabolic oxidation constants given in Table 2 when compared to literature data ${ }^{2,6}$. Figure 5 shows a comparison between the parabolic oxidation constants for the 430A and 430E steels and the parabolic oxidation constant of the 439 ferritic stainless steel previously studied by the authors ${ }^{2}$. As mentioned above, for the $430 \mathrm{~A}$ steel there is an apparent anomaly probably due to the

Table 2. Parabolic oxidation constants.

\begin{tabular}{ccc}
\hline $\mathrm{T}\left({ }^{\circ} \mathrm{C}\right)$ & \multicolumn{2}{c}{$\mathrm{k}_{\mathrm{p}}\left(\mathrm{g}^{2} \mathrm{~cm}^{-4} \mathrm{~s}^{-1}\right)$} \\
\cline { 2 - 3 } & 430 A steel & 430 E steel \\
\hline 850 & $1.9 \times 10^{-13}$ & $5.6 \times 10^{-14}$ \\
900 & $1.5 \times 10^{-13}$ & $2.4 \times 10^{-13}$ \\
950 & $2.3 \times 10^{-13}$ & $5.3 \times 10^{-13}$ \\
\hline
\end{tabular}



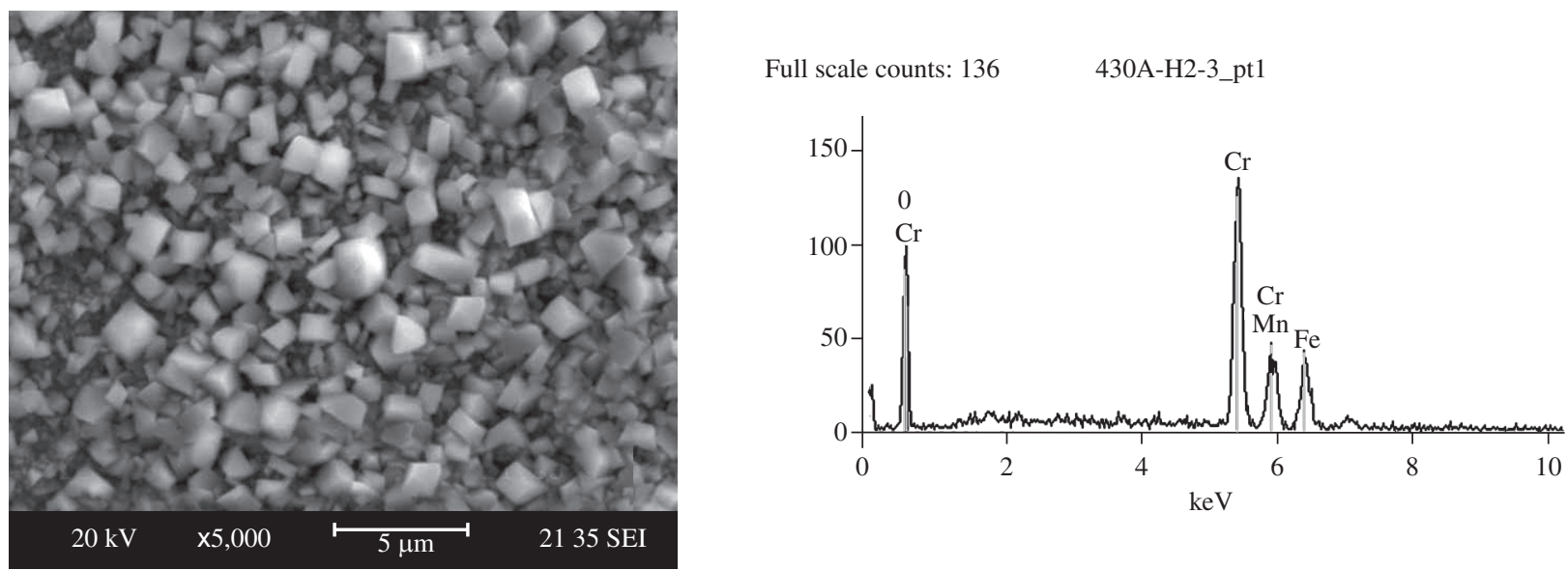

(a)

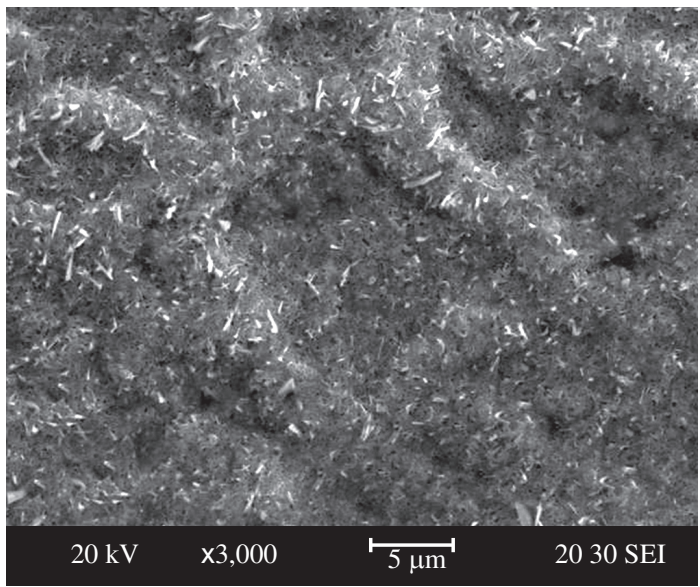

Full scale counts: $1045 \quad$ 430A-H2-10_pt9

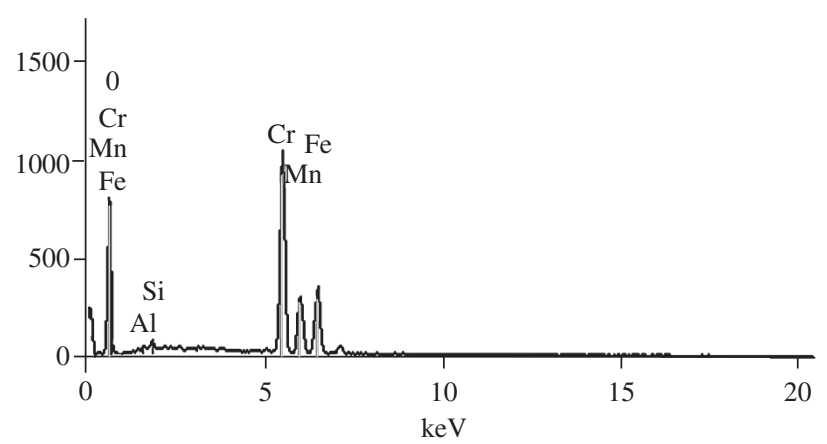

(b)

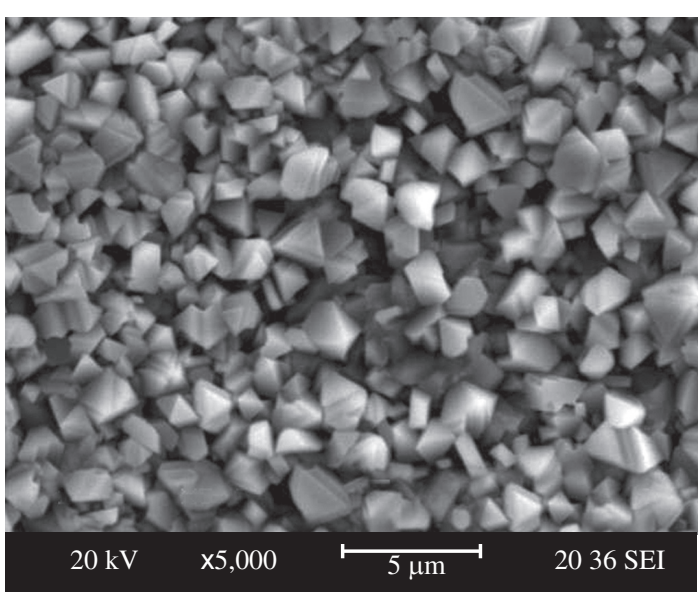

Full scale counts: 2777 430A-H2-19_pt3

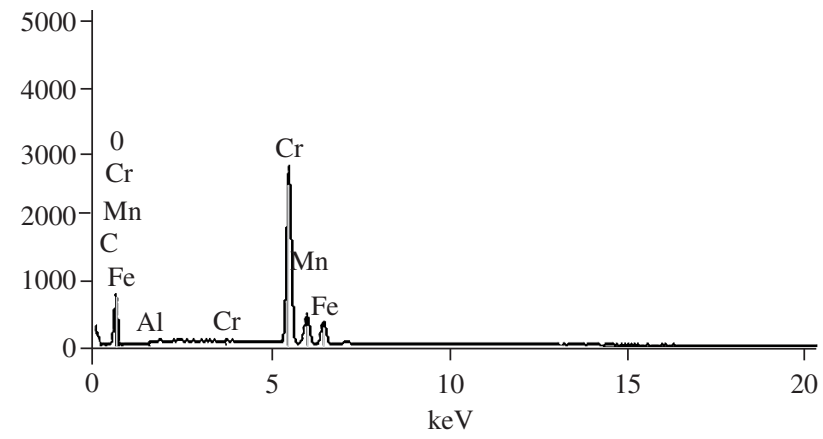

(c)

Figure 3. Microstructure and EDS analyses of the oxide films grown on the 430A steel.

phase transformation of these steel at about $860^{\circ} \mathrm{C}$, which may be responsible for the small variation of the $\mathrm{k}_{\mathrm{p}}$ values between 850 and $950{ }^{\circ} \mathrm{C}$. Indeed, at $850{ }^{\circ} \mathrm{C}$, the AISI $430 \mathrm{~A}^{\mathrm{p}}$ structure is ferritic and consequently the cation diffusion coefficients in the steel are faster than in an austenitic (or biphased) structure which is obtained at 900 and $950{ }^{\circ} \mathrm{C}^{7}$. Consequently, the chromium atom fluxes are greater and the chromia film growth is faster. This is confirmed by the fact that the microstructure obtained at $850{ }^{\circ} \mathrm{C}$ is similar to that obtained at $950{ }^{\circ} \mathrm{C}$. On the other hand, the $\mathrm{k}_{\mathrm{p}}$ of the $430 \mathrm{E}$ steel depends on the temperature according to the Arrhenius equation: $\mathrm{k}_{\mathrm{p}}\left(\mathrm{g}^{2} \mathrm{~cm}^{-4} \mathrm{~s}^{-1}\right)=$ $5.9 \times 10^{-2} \exp [-258(\mathrm{~kJ} / \mathrm{mol}) / \mathrm{RT}]$. The activation energy of $258 \mathrm{~kJ}$. $\mathrm{mol}^{-1}$ is similar to that of $251 \mathrm{~kJ} \cdot \mathrm{mol}^{-1}$ observed for the parabolic oxidation constant of the 439 stainless steel $^{2}$, and corresponds to the value given in literature for chromia scale growth ${ }^{4,6}$. It is worth 


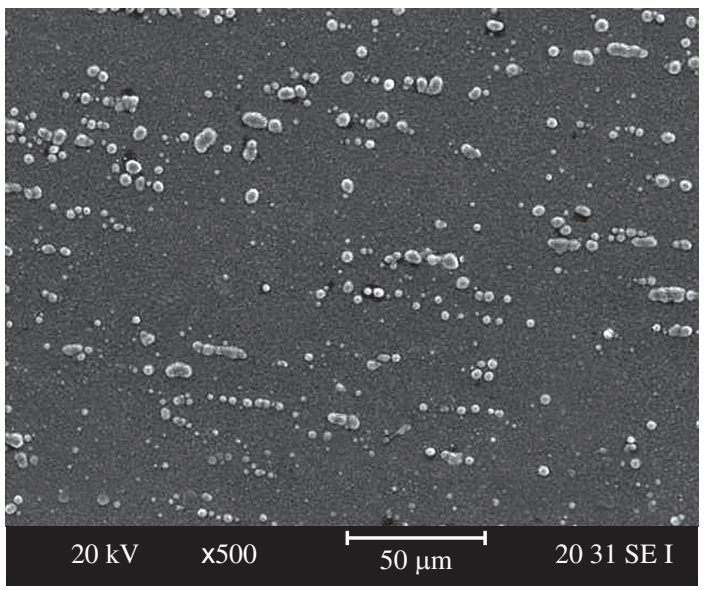

Full scale counts: 339 430E_850-_H2_1pt3

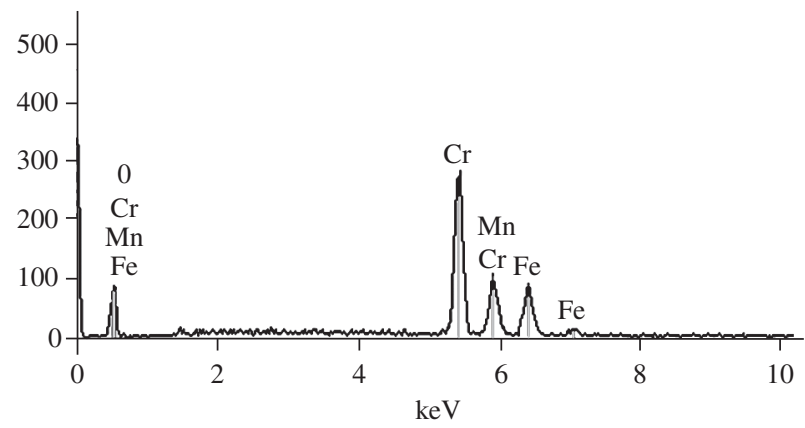

(a)

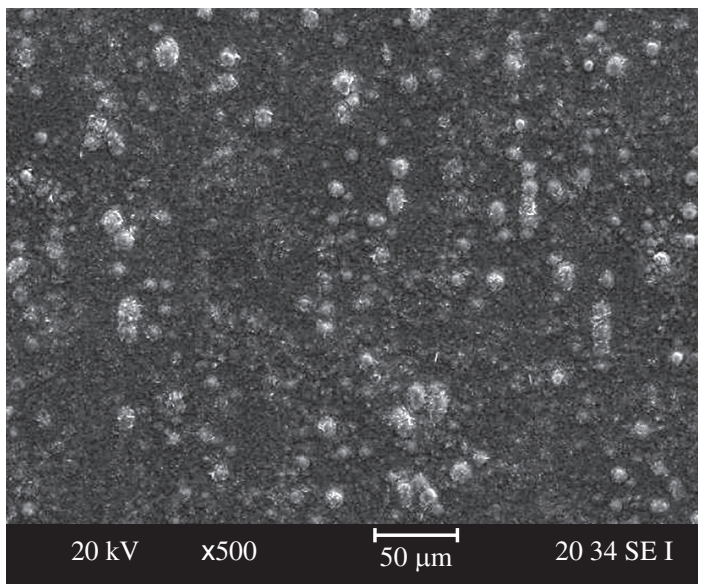

Full scale counts: 375 430E_900_H2_1_pt3

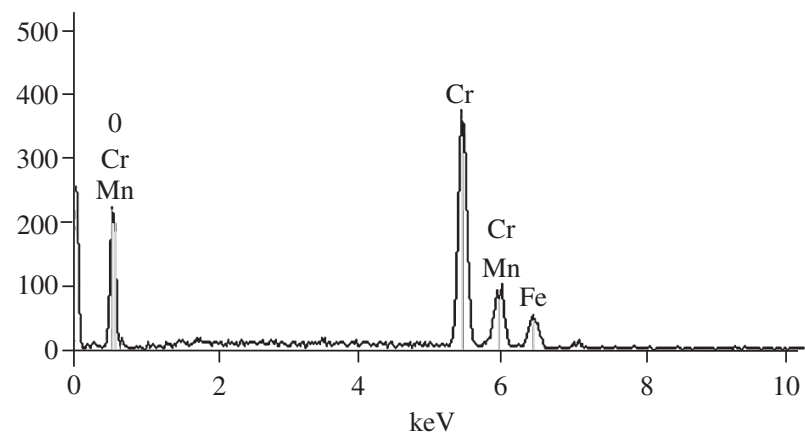

(b)

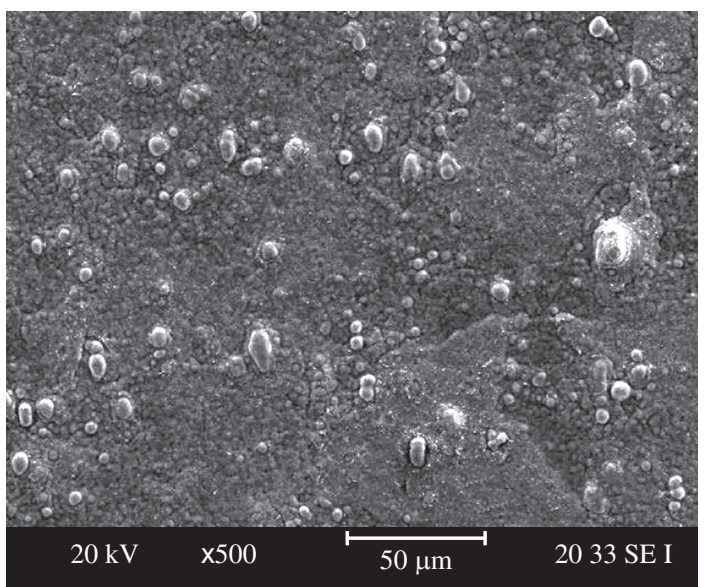

Full scale counts: 355 430E_950_H2_1_pt2

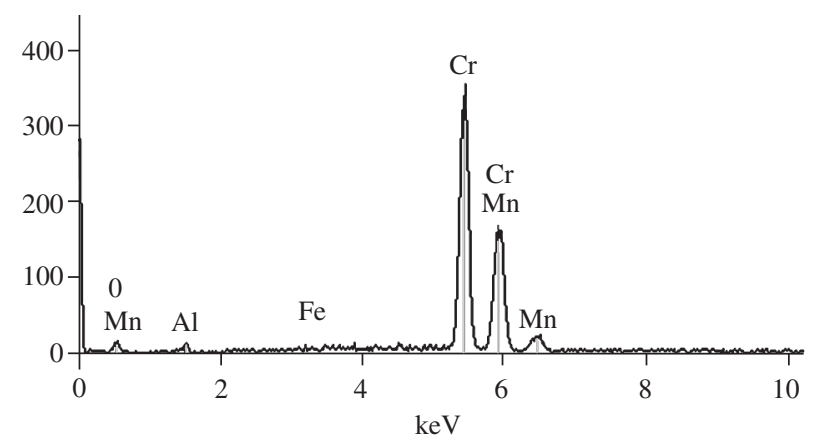

(c)

Figure 4. Microstructure and EDS analyses of the oxide films grown on the 430E steel.

noting that, at each temperature, there is a given oxygen partial pressure value. Our feeling is that the effect of the oxygen partial pressure on the oxidation constant, between $\mathrm{pO}_{2}=1.46 \times 10^{-20}$ and $1.3 \times 10^{-18}$ atm, should be negligible. Indeed, in previous studies ${ }^{1,2}$, it was observed that the oxidation constant of the AISI 439 ferritic steel did not practically show significant variation with the oxygen pressure for the extreme values of $1 \mathrm{~atm}$ and $1.46 \times 10^{-20} \mathrm{~atm}$. In ad- dition, other studies ${ }^{8}$ show that the oxygen and chromium diffusivities in $\mathrm{Cr}_{2} \mathrm{O}_{3}$ do not depend on the oxygen pressure. As a general case, the $430 \mathrm{~A}$ and $430 \mathrm{E}$ stainless steel are used for applications at low or room temperature, and the knowledge of their oxidation kinetics at high temperatures is particularly important in the field of the hot rolling. On the other hand, the 439 steel has been used for replacing the 304 austenitic stainless steel for industrial applications at high 
temperature as, for instance, in exhaust line systems, in presence of low oxygen pressure gas ${ }^{1}$. According to Figure 5 , the $430 \mathrm{~A}$ and $430 \mathrm{E}$ stainless steels have higher oxidation resistance than the 439 stainless steel in $\mathrm{Ar} / \mathrm{H}_{2} / \mathrm{H}_{2} \mathrm{O}$ atmosphere, i.e., in low oxygen pressure, at high temperatures. In spite of the particular behavior of the AISI 430A, its oxidation rate takes place in a limited range as compared to the oxidation rate of the 430E steel as shown in Figure 6.

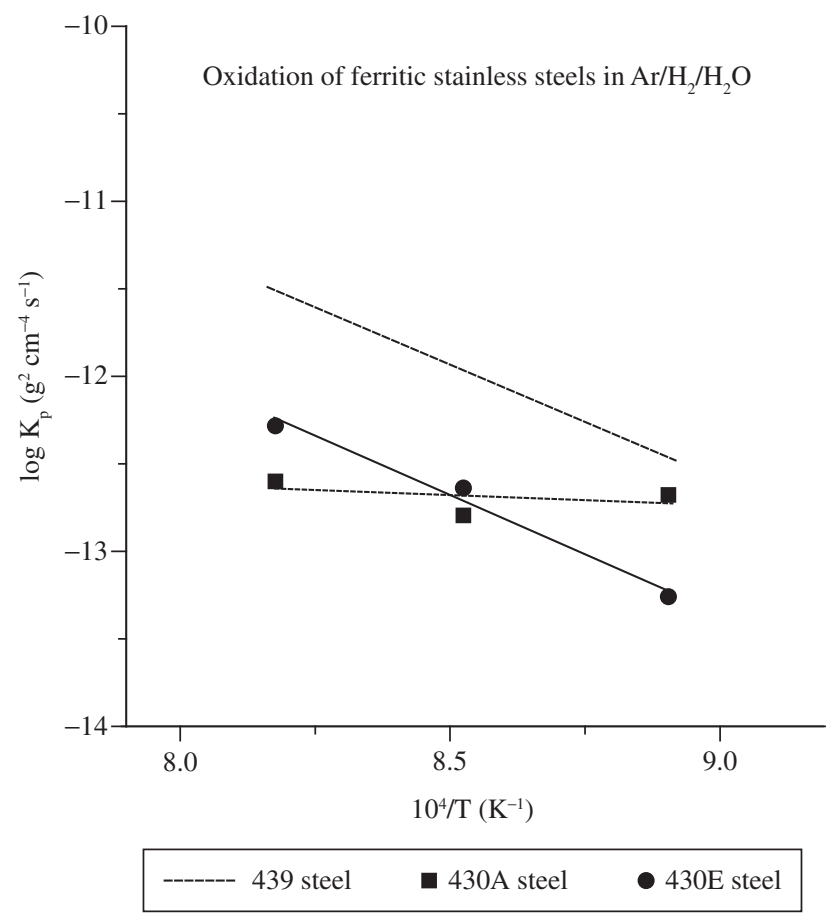

Figure 5. Arrhenius plot of the parabolic oxidation constants of 430A, 430E and 439 steels in $\mathrm{Ar} / \mathrm{H}_{2} / \mathrm{H}_{2} \mathrm{O}$.

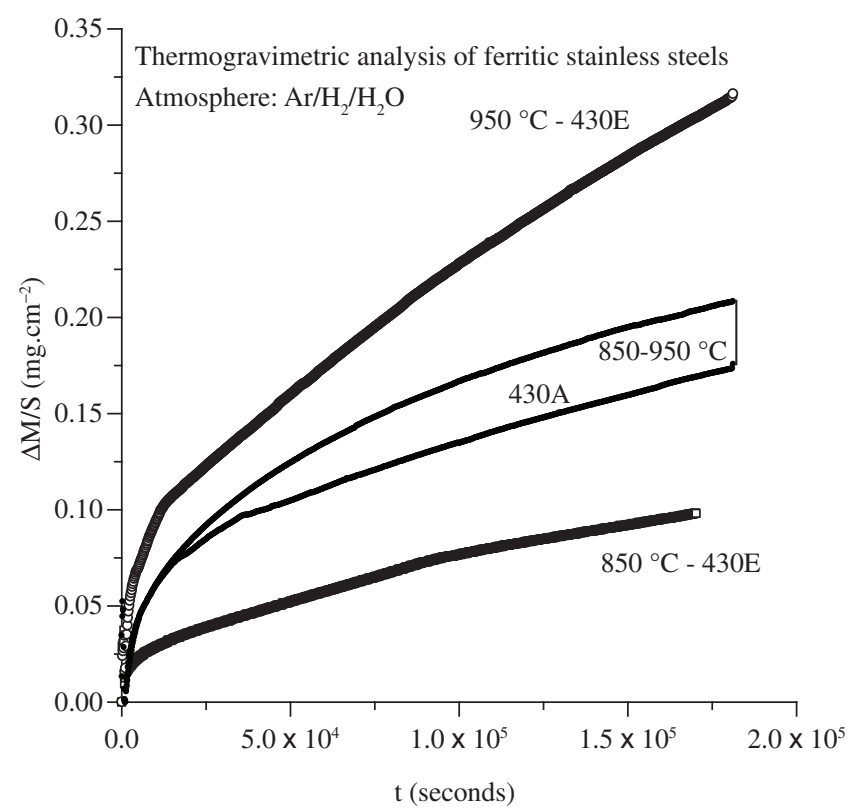

Figure 6. Comparison of the mass gains as a function of time for the $430 \mathrm{~A}$ and $430 \mathrm{E}$ steels oxidized at 850,900 and $950^{\circ} \mathrm{C}$ in $\mathrm{Ar} / \mathrm{H}_{2} / \mathrm{H}_{2} \mathrm{O}$.
For the oxygen pressure established in the $\mathrm{Ar} / \mathrm{H}_{2} / \mathrm{H}_{2} \mathrm{O}$ gas mixture, iron oxide is thermodynamically unstable, while chromia is stable. Therefore, chromia can grow and it is the major oxide formed by the oxidation of these steels in $\mathrm{Ar} / \mathrm{H}_{2} / \mathrm{H}_{2} \mathrm{O}$, which was confirmed by EDS analyses in both steels. Mn and Fe were also detected by EDS analyses of oxidized surface of both steels. Traces of Si were also observed mainly in the film grown on the 430A steel. The oxide scale formed on the 430A steel was continuous and homogeneous. Preferential oxidation at the grain boundary of the metallic substrate was observed at $900{ }^{\circ} \mathrm{C}$, as shown in Figure $3 \mathrm{~b}$. This is due to the fact that with a ferritic-austenitic structure, as mentioned before, the diffusivities of $\mathrm{Cr}$, and other transition metals, in the substrate are slower than with a ferritic structure. Thus, grain boundaries in the substrate provide a greater chromium flux than in the bulk, which leads to a preferential oxidation along substrate grain boundaries.

The oxide scale formed on the $430 \mathrm{E}$ steel was also continuous, but with spherical particles of about 2-4 $\mu \mathrm{m}$ in diameter dispersed on the oxide scale (Figures 4a,c and Figures 7a,b). The chemical analyses

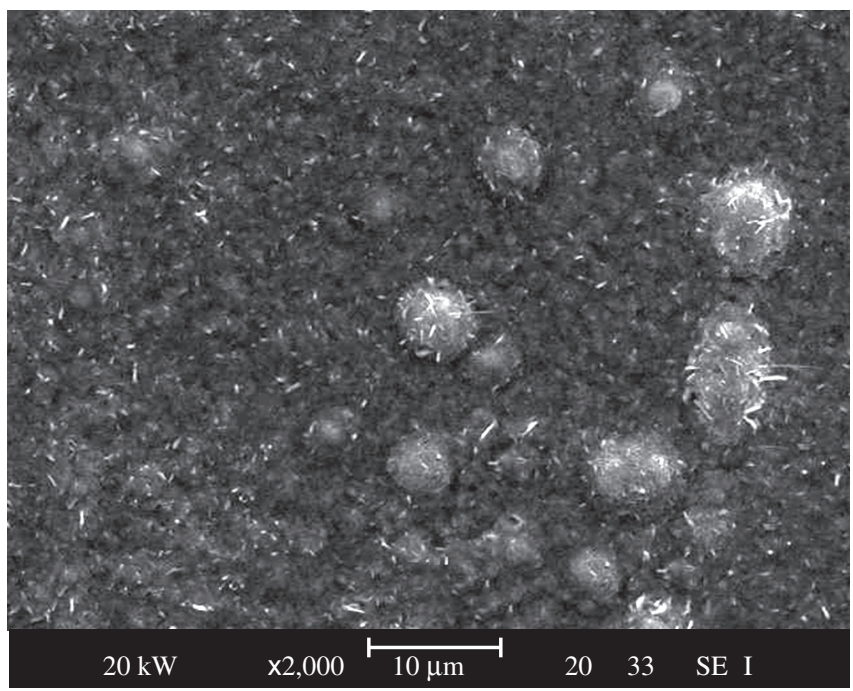

(a)

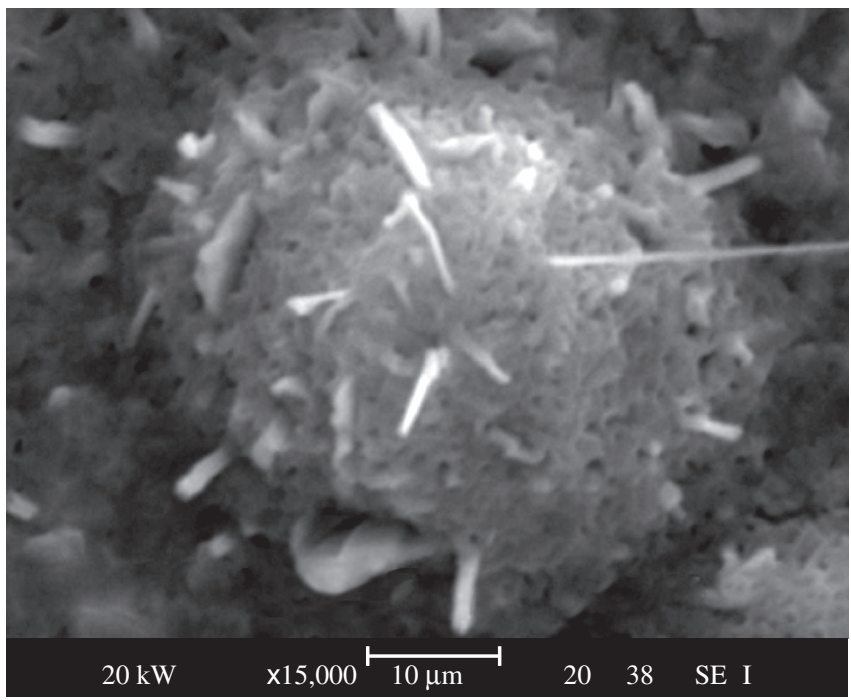

(b)

Figure 7. a) Spherical particles dispersed on the oxide film grown on the $430 \mathrm{E}$ steel after oxidation at $950{ }^{\circ} \mathrm{C}$, for 50 hours. b) Whiskers emanating from the particle. 
by EDS showed that the composition of these particles was similar to that of the oxide scale. For oxide film formed on the 430E steel, the higher the temperature, the higher the $\mathrm{Cr}$ content. The Mn content in the oxide scale increased with increasing temperature for the $430 \mathrm{E}$ steel. On the other hand, the Fe content was progressively reduced with increasing temperature, which indicates that the detected iron is preferentially coming from the substrate, due to the small thickness of the oxide film. In some points analyzed only $\mathrm{Cr}$ and $\mathrm{Mn}$ were found (Figure 4c), which suggests the formation of $\mathrm{MnCr}_{2} \mathrm{O}_{4}$ spinel particles on the outer surface.

For the 430A steel, Cr was the major component, and similar Mn and $\mathrm{Fe}$ contents were observed approximately in the same proportions at all temperatures. The presence of $\mathrm{Mn}$ on chromia forming alloys was recently discussed by Sabioni et al. ${ }^{9}$. Based on their study of Mn diffusion in chromia films, they suggested that Mn-rich particles on the outer surface results from the initial oxidation, due to the fact that manganese affinity for oxygen is greater than chromium affinity. This is followed, on a second stage, by manganese ion diffusion through chromia towards the outer surface of the scale. The amount of Mn on the top of the film is limited by the small amount of Mn in the steel, compared to chromium content, and may form a spinel oxide. The authors have shown that chromia does not act as a barrier for iron diffusion ${ }^{10}$. Therefore, the iron found in the film can be due either to the iron diffusion from the metallic substrate into the chromia film, or to iron detected in the substrate.

\section{Conclusions}

The oxidation experiments of the 430A and 430E ferritic stainless steels in the range of $850-950{ }^{\circ} \mathrm{C}$ in $\mathrm{Ar} / \mathrm{H}_{2} / \mathrm{H}_{2} \mathrm{O}$ atmosphere, under oxygen partial pressures lower than $1.3 \times 10^{-18} \mathrm{~atm}$, show different oxidation behaviors. The oxidation rate of the 430A steel shows low dependence on temperature, while the oxidation of the 430E follows an Arrhenius law, with an activation energy corresponding to the chromia scale growth. At $850{ }^{\circ} \mathrm{C}$, the oxidation of the $430 \mathrm{~A}$ steel is greater than that of the $430 \mathrm{E}$ steel, but above $900{ }^{\circ} \mathrm{C}$ the oxidation of the 430A steels is lower than that of the $430 \mathrm{E}$ steel. This particular behavior for the $430 \mathrm{~A}$ is associated to its phase transformation at
$860{ }^{\circ} \mathrm{C}$. In the experimental conditions used in this work, the $430 \mathrm{~A}$ and $430 \mathrm{E}$ steels are more resistant to the oxidation than the 439 ferritic steel, which is usually designed for high temperature applications.

No particular role of the $\mathrm{Nb}$ on the oxidation of the $430 \mathrm{E}$ steel was observed.

\section{Acknowledgments}

The authors are grateful to FAPEMIG (Brazil), CNPq (Brazil) and CNRS (France) for financial support.

\section{References}

1. Sabioni ACS, Huntz AM, Luz EC, Mantel M, Haut C. Comparative Study of High Temperature Oxidation Behavior in AISI 304 and AISI 439 Stainless Steels. Materials Research 2003; 6(2):179-185.

2. Huntz AM, Haut C, Sévérac C, Herbst M, Resende FCT, Sabioni ACS. Oxidation of AISI 304 and AISI 439 Stainless Steels. Materials Science and Engineering A 2007; 447(1-2):266-276.

3. Arcelor Mittal Timóteo; 2007.

4. Kofstad P. High Temperature Corrosion. 1st ed. London: Elsevier Applied Science; 1988.558 p.

5. Wagner C. Diffusion and High Temperature Oxidation of Metals. Atom Movements. Cleveland: ASM Seminar; 1951. p. 153-173.

6. Atkinson A. Transport processes during the growth of oxide films at elevated temperature. Reviews of Modern Physics 1985; 57(2):437-470.

7. Antoni L, Herbelin JM. Cyclic Oxidation of High Temperature Materials. Proceedings of EFC Workshop; 1999; Frankfurt/Main: European Federation of Corrosion Publications; 1999; 27:187-197.

8. Sabioni, ACS, Lesage B, Huntz AM, Pivin JC and Monty C. Self-diffusion in $\mathrm{Cr}_{2} \mathrm{O}_{3}$. Part I: Chromium diffusion in single crystals. Philosophical Magazine A 1992; 66(3):333-350.

9. Sabioni ACS, Huntz AM, Borges LC, Jomard F. First study of manganese diffusion in $\mathrm{Cr}_{2} \mathrm{O}_{3}$ polycrystal and thin films. Philosophical Magazine, 2007; 87(12):1921-1937.

10. Sabioni ACS, Huntz AM, Silva F, Jomard F. Diffusion of iron in $\mathrm{Cr}_{2} \mathrm{O}_{3}$ : polycrystals and thin films. Materials Science and Engineering: A 2005; 392(1-2):254-261. 